\title{
DESULPHURIZATION STUDY OF PETROLEUM PRODUCTS THROUGH EXTRACTION WITH AQUEOUS IONIC LIQUIDS
}

\author{
MOHAMMAD SHAKIRULLAH, IMTIAZ AHMAD, WAQAS AHMAD, MOHAMMAD ISHAQ
}

Institute of Chemical Sciences, University of Peshawar, Pakistan

(Received: April 20, 2009 - Accepted: May 14, 2010)

\begin{abstract}
Desulphurization of jet fuel, diesel oil, heavy residue and commercial furnace oil is carried out through extraction with aqueous solutions of sodium chloride, barium chloride, sodium hydroxide, mercury chloride, arsenic trioxide, potassium iodide, lead acetate, calcium hydroxide, zinc chloride, aluminum chloride, hydrochloric acid and sulphuric acid. Among the solutions used, $\mathrm{HgCl}_{2}$ and $\mathrm{Ca}(\mathrm{OH})_{2}$ were found to be the most efficient for the removal of sulphur compounds from the fractions understudy at $40{ }^{\circ} \mathrm{C}$ temperature and $30 \mathrm{~min}$ of shaking time. The total sulphur depletion of $60 \%$ and $58 \%$ has been achieved in case of jet fuel oil, $71 \%$ and $62 \%$ in case of diesel oil, $68 \%$ and $67 \%$ in case of heavy residue and $67 \%$ and $69 \%$ in case of commercial furnace oil with $10 \% \mathrm{HgCl}_{2}$ and $5 \% \mathrm{Ca}(\mathrm{OH})_{2}$ aqueous solutions, respectively.
\end{abstract}

Key Words: Desulphurization, Ionic Liquids, Petroleum, Environment.

\section{INTRODUCTION}

The presence of sulphur compounds in petroleum is always objectionable due to their process and environmental problems. Sulphur occurs in many forms in petroleum like free sulphur, $\mathrm{H}_{2} \mathrm{~S}$, marcaptans, sulphides, disulphide and thiophenes ${ }^{1}$. These compounds are undesirable in the petroleum because of their potential corrosion problems in refining process ${ }^{2-4}$. Further more, these compounds are responsible for environmental problems ${ }^{5-8}$. Keeping in view the hazardous effects of the sulphur in petroleum, much attention is being paid to desulphurization in the recent years to protect the environment ${ }^{9,10}$. Primitive techniques such as doctor sweetening was developed in 1860's, while the others developed later on were based on the oxidation of thioles to sulphides and disulphides ${ }^{11,12}$. These processes were used to eliminate the corrosion and bad odour but not the sulphur compounds. Later on desulphurization in the presence of hydrogen was practiced. In conventional hydrodesulphurization (HDS), severe operating conditions of high temperature and pressure are unavoidable. Moreover, high consumptions of hydrogen and expensive cobalt molybdenum catalysts are other disadvantages of the method ${ }^{13}$. Research is underway to improve the profitability of the process ${ }^{14-15}$. Even with the conventional processes, it is difficult to reduce the sulfur content to less than $15 \mathrm{ppm}$. Therefore, new economical and more effective methods are sought through out the world ${ }^{16-18}$.

Among the new methods, desulphurization through ionic solutions is gaining importance due to no hydrogen consumption, and much less sever conditions are required. The process is limited to desulphurization of lighter petroleum products ${ }^{19-21}$. In case of high boiling fractions, only small degree of desulphurization is achieved due to increase in viscosity which alters the interfacial properties and solubility of these fractions ${ }^{22}$. The process awaits further development for meaning full desulphurization of heavy petroleum fractions.

In the present work, we report on the application of some ionic solutions for desulphurization of various petroleum fractions. The comparative study of the various aqueous ionic solutions on the extraction of the sulphur compounds has also been carried out

\section{EXPERIMENTAL}

\section{Sample collection and fractionation}

Crude oil sample of Jhal Magsi oil field (Balochistan, Pakistan) was obtained through Oil and Gas Development Corporation Limited (OGDCL), Islamabad, Pakistan. The sample was kept in a metal can. The crude oil was distilled using distillation apparatus (Stanhope Seta limited model 118600) adopting IP-24/84 method to obtain distillate fractions like kerosene, diesel, heavy residue and commercial furnace oil. The fractions obtained were characterized by determining various physico-chemical parameters by employing standard ASTM and IP procedures. The analysis of Jhal Magsi crude oil distillate fractions are provided in Table 1.
Table 1. Physico-chemical characteristics of Jhal Magsi crude oil and its distillate fractions.

\begin{tabular}{|c|c|c|c|c|}
\hline Characteristics & Kerosene & Diesel & $\begin{array}{c}\text { Heavy } \\
\text { residue }\end{array}$ & $\begin{array}{c}\text { Furnace } \\
\text { oil }\end{array}$ \\
\hline Specific gravity & 0.7902 & 0.8360 & 0.8635 & 0.9480 \\
\hline API gravity & 45.810 & 37.750 & 32.760 & 17.750 \\
\hline Kinematic visco & 2.217 & 3.814 & 4.437 & 5.107 \\
\hline (cSt) at $100^{\circ} \mathrm{F}$ & 60.0 & 66.0 & 74.0 & 82.0 \\
\hline Aniline point ( $\left.{ }^{\circ} \mathrm{C}\right)$ & 46.3 & 52.1 & 138.0 & 171.0 \\
\hline Flash point $\left({ }^{\circ} \mathrm{C}\right)$ & 0.065 & 0.05 & 0.205 & 0.33 \\
\hline Ash contents (wt \%) & & & \\
\hline Conradson carbon residue & 0.18 & 0.21 & 2.15 & 3.21 \\
\hline \multicolumn{6}{|c|}{$(\mathrm{wt} \%)$} & 1.184 & 1.564 & 1.217 & 3.309 \\
\hline Total sulphur (wt \%) &
\end{tabular}

Desulphurization of fractions

$10 \%$ aqueous solutions of sodium chloride, sodium hydroxide, barium chloride, mercury chloride, potassium iodide, lead acetate, zinc chloride and aluminum chloride, $5 \%$ aqueous solutions of arsenic trioxide and calcium hydroxide, and $1 \mathrm{~N}$ aqueous solutions of hydrochloric acid and sulphuric acid were prepared.

$20 \mathrm{ml}$ of the petroleum fraction was taken in the Erlenmeyer flask. $20 \mathrm{ml}$ of the aqueous solution was added. Flask was fixed in the sonicator and the temperature was kept at $40{ }^{\circ} \mathrm{C}$. The mixture was shaken for $30 \mathrm{~min}$ with a 2 min of rest between successive sonication of $5 \mathrm{~min}$. After a total of $30 \mathrm{~min}$ sonication, the mixture was transferred to a separating funnel and was kept for $10 \mathrm{~min}$ to allow complete separation of lower solvent layer from the upper oily layer. The two layers were then separated and the oily layer was analyzed for the level of total sulphur.

Sulphur determination and fractions characterization

Total sulphur in the petroleum fractions was determined by carbon sulphur analyzer (Leco SC-144DR equipped with computer software). Total sulphur was also determined by bomb washing method (ASTM designation D 129-83 and IP designation 61/84). Infra red spectra of the fractions were taken by FTIR Spectrophotometer (Model No. FTIR-8201 ICP, Shimadzu, Japan). 


\section{RESULTS AND DISCUSSION}

\section{Desulphurization through liquid-liquid extraction}

Liquid-liquid extraction is extensively used in the purification of organic compounds, and the same is very helpful in removing the unwanted sulphur compounds from the petroleum hydrocarbons.

The process of extraction is concerned with the distribution law or partition law which states that if to a system of two liquid layers, made of two immiscible or slightly miscible components, is added quantity of a third substance which is soluble in both layers, then the substance distributes itself between the two layers so that the ratio of concentration in one solvent to the concentration in the other solvent remains constant at constant temperature. It is assumed that the molecular state of the substance is same as in both solvents. If $\mathrm{C}_{\mathrm{A}}$ is the concentration in the layer $\mathrm{A}$ and $\mathrm{C}_{\mathrm{B}}$ is the concentration in the layer $\mathrm{B}$, then at constant temperature:

$$
\mathrm{C}_{\mathrm{A}} / \mathrm{C}_{\mathrm{B}}=\text { Constant }=\mathrm{k}
$$

The constant $\mathrm{k}$ is termed as the distribution or partition coefficient. As very rough approximation the distribution coefficient may be measured equal to the ratio of the solubilities in the two solvents. Organic sulphur compounds are mostly soluble in the polar solvents; besides the solvents having affinity for the sulphur compounds can be more helpful in their extraction. Thus, this technique was applied in the present study by using different solvent systems at same temperature and at the same contact time.

Desulphurization of kerosene oil, diesel oil, heavy residue and commercial furnace oil was conducted by liquid-liquid extraction at same temperature (40 ${ }^{\circ} \mathrm{C}$ ) and same shaking time $(30 \mathrm{~min})$. Sulphur depletion for these fractions expressed as \% desulphurization is provided in the Table 2 and Figure 1 as their comparative study.

Table 2. \% Desulphurization of distillate fraction after extraction with various ionic solutions.

\begin{tabular}{|c|c|c|c|c|}
\hline \multirow[t]{2}{*}{ Solution } & \multicolumn{4}{|c|}{$\%$ Desulphurization } \\
\hline & Kersone & Diesel & $\begin{array}{l}\text { Heavy } \\
\text { Residue }\end{array}$ & Furnace oil \\
\hline $\mathrm{NaCl}(10 \%)$ & 37.95 & 35.80 & 32.13 & 20.85 \\
\hline $\mathrm{BaCl}_{2}(10 \%)$ & 15.66 & 31.30 & 61.54 & 13.23 \\
\hline $\mathrm{NaOH}(10 \%)$ & 59.62 & 64.81 & 59.33 & 62.95 \\
\hline $\mathrm{HgCl}_{2}(10 \%)$ & 60.11 & 71.75 & 68.33 & 67.68 \\
\hline $\mathrm{AsO}_{3}(5 \%)$ & 45.47 & 59.83 & 61.19 & 65.61 \\
\hline KI $(10 \%)$ & 20.49 & 43.78 & 45.19 & 38.75 \\
\hline $\mathrm{Pb}$-acetate $(10 \%)$ & 49.77 & 40.28 & 46.64 & 46.50 \\
\hline $\mathrm{Ca}(\mathrm{OH})_{2}(5 \%)$ & 58.36 & 62.13 & 67.22 & 69.77 \\
\hline $\mathrm{ZnCl}_{2}(10 \%)$ & 48.25 & 52.89 & 35.86 & 42.44 \\
\hline $\mathrm{AlCl}_{3}(10 \%)$ & 12.37 & 30.70 & 65.18 & 17.57 \\
\hline $\mathrm{HCl}(1 \mathrm{~N})$ & 53.65 & 56.22 & 58.40 & 65.11 \\
\hline $\mathrm{H}_{2} \mathrm{SO}_{4}(1 \mathrm{~N})$ & 35.91 & 38.78 & 48.11 & 32.39 \\
\hline
\end{tabular}


processes like Howe-Baker process and sulfining process ${ }^{9}$, where it is used for sweetening process in which the sulphur bearing molecules are oxidized to less harmful sulphides, but not for the removal of the sulphur bearing molecules. It might be suggested that due to high concentration, sulphuric acid failed to extract and consequently oxidized the sulphur compounds due to which it gave low desulphurization yield.

\section{Desulphurization of Diesel oil}

In case of diesel oil, the highest desulphurization yields of $64.95,71.74$, $59.83,62.21$ and $65.21 \%$ are achieved with aqueous solutions of $\mathrm{HgCl}_{2}(10 \%)$, $\mathrm{HCl}(1 \mathrm{~N}), \mathrm{Ca}(\mathrm{OH})_{2}(5 \%), \mathrm{NaOH}(10 \%)$ and $\mathrm{AsO}_{3}(5 \%)$, respectively. On the other hand, relatively poor desulphurization yields of $35.80,31.30,43.77$, $40.28,52.89,30.69$ and $38.78 \%$ are attained with the solutions of $\mathrm{NaCl}(10 \%)$, $\mathrm{BaCl}_{2}(10 \%), \mathrm{KI}(10 \%), \mathrm{Pb}$-acetate $(10 \%), \mathrm{ZnCl}_{2}(10 \%), \mathrm{AlCl}_{3}(10 \%)$ and $\mathrm{H}_{2} \mathrm{SO}_{4}(1 \mathrm{~N})$, respectively (Table.2).

Table 3. Sulphur contents of distillate fraction after extraction with various ionic solutions.

\begin{tabular}{|c|c|c|c|c|}
\hline \multirow[t]{2}{*}{ Solution } & \multicolumn{4}{|c|}{$\%$ Desulphurization } \\
\hline & Kersone* & Diesel** & $\begin{array}{c}\text { Heavy } \\
\text { Residue*** }\end{array}$ & $\begin{array}{l}\text { Furnace } \\
\text { oil } * * * *\end{array}$ \\
\hline $\mathrm{NaCl}(10 \%)$ & 0.96 & 0.99 & 0.75 & 2.55 \\
\hline $\mathrm{BaCl}_{2}(10 \%)$ & 1.31 & 1.06 & 0.43 & 2.80 \\
\hline $\mathrm{NaOH}(10 \%)$ & 0.63 & 0.55 & 0.45 & 1.20 \\
\hline $\mathrm{HgCl}_{2}(10 \%)$ & 0.62 & 0.44 & 0.35 & 1.04 \\
\hline $\mathrm{AsO}_{3}(5 \%)$ & 0.84 & 0.62 & 0.43 & 1.11 \\
\hline KI $(10 \%$ & 1.23 & 0.87 & 0.61 & 1.98 \\
\hline $\mathrm{Pb}$-acetate $(10 \%)$ & 0.78 & 0.93 & 0.61 & 1.73 \\
\hline $\mathrm{Ca}(\mathrm{OH})_{2}(5 \%)$ & 0.65 & 0.59 & 0.36 & 0.98 \\
\hline $\mathrm{ZnCl}_{2}(10 \%)$ & 0.80 & 0.73 & 0.71 & 1.86 \\
\hline $\mathrm{AlCl}_{3}(10 \%)$ & 1.36 & 1.07 & 0.39 & 2.66 \\
\hline $\mathrm{HCl}(1 \mathrm{~N})$ & 0.72 & 0.68 & 0.46 & 1.13 \\
\hline $\mathrm{H}_{2} \mathrm{SO}_{4}(1 \mathrm{~N})$ & 0.76 & 0.95 & 0.58 & 2.18 \\
\hline
\end{tabular}

* sulphur contents of original kerosene $1.19 \% \mathrm{wt},{ }^{* *}$ original diesel 1.54 $\% \mathrm{wt}$,

$* * *$ virgin heavy residue $1.11 \% \mathrm{wt}$ and $* * * *$ virgin furnace oil $2.23 \% \mathrm{wt}$

Sulphur compounds contained in diesel oil include high molecular weight sulphides, disulphids, thiophenes, benzothiophenes and dibenzothiophenes. The results of desulphurization closely resembles to that obtained in case of kerosene oil. As mentioned earlier, $\mathrm{NaOH}$ has been very active in sweetening processes suggesting its high desulphurization potential that is probably attributed to its high alkaline nature. In this aqueous alkaline layer, the highly acidic sulphur compounds readily distribute from the oily phase, which can easily be extracted. The same approach can also be used to explain the high desulphurization yield attained with $\mathrm{Ca}(\mathrm{OH})_{2} \mathrm{HgCl}_{2}$ has also shown promising sulphur depletion. The reason is high affinity of metal chlorides towards sulphur compounds in term of reactivity, which has been proved in the earlier work ${ }^{26-}$ ${ }^{27}$. $\mathrm{HgCl}_{2}$ extraction is associated with the formation of gummy precipitate, which is probably considered to be solid mercuric sulphides produced during the reaction between mercuric chloride and mercaptans in the diesel oil. On the other hand, the poor desulphurization yields with $\mathrm{NaCl}, \mathrm{BaCl}_{2}, \mathrm{ZnCl}_{2}$ and $\mathrm{AlCl}_{3}$ show that these solutions are unable to extract sulphides or thiophenes from organic phase and their cations lack strong interaction with sulphur moieties like $\mathrm{Hg}$. Low desulphurization yields of KI and lead acetate, may also be explained on the same basis.

Promising results of sulphur depletion exhibited by arsenic oxide in case of diesel oil may be explained on the basis of reactive nature of arsenic. Similarly, the efficient performance of $\mathrm{HCl}$ in desulphurization may be explained in the same way as in case of kerosene oil. Sulfuric acid has been although used for the removal of sulphur in a varity of conventional processes. In the present study, sulphuric acid did not show promising results. The reason may be due to high concentration of the acidic solution which is unsuitable for dissolution of the sulphur bearing molecules, which are also itself acidic in nature.

\section{Desulphurization of Heavy residue}

The sulphur compounds present in the heavy residue are mostly high molecular weight sulphides and aromatic hetero cyclic sulphur compounds particularly thiophene, benzothiophene and dibenzothiophene. The percentage of aromatic sulphur heterocycles is higher than the aliphatic sulphides and marcaptans. The extraction of these compounds is relatively difficult than mercaptans. From the Table. 2 it is clear that in case of heavy residue, maximum desulphurization activity is achieved with $\mathrm{HgCl}_{2}(10 \%), \mathrm{HCl}(1 \mathrm{~N}), \mathrm{Ca}(\mathrm{OH})_{2}(5$ $\%), \mathrm{NaOH}(10 \%), \mathrm{BaCl}_{2}(10 \%)$ and $\mathrm{AsO}_{3}(5 \%)$, which have attained 59.33, $68.35,61,67.22,61.53$ and $58.11 \%$ desulphurization, respectively. While the rest of the solutions have exhibited poor desulphurization activity. In case of extraction with $\mathrm{NaCl}(10 \%), \mathrm{KI}(10 \%), \mathrm{Pb}$-acetate $\left(10 \%\right.$, ) $\mathrm{ZnCl}_{2}(10 \%$, $\mathrm{AlCl}_{3}(10 \%)$ and $\mathrm{H}_{2} \mathrm{SO}_{4}(1 \mathrm{~N})$, desulphurization yields obtained were 32.13 , $45.18,46.64,35.85,45.18$ and $48.40 \%$, respectively.

The data in the Table.2 shows that the desulphurization yields with $\mathrm{NaOH}$ and $\mathrm{Ca}(\mathrm{OH})_{2}$ are very high, which can be explained on the basis of their highly alkaline nature which provides efficient medium for the dissolution of acidic sulphur compounds. Caustic treatment has been practiced for desulphurization of crude oil and lighter petroleum fractions earlier but not for heavy residue. The present observation evident that the same practice is also effective in the removal of aromatic sulphur compounds. High desulphurization yield with $\mathrm{HgCl}_{2}$ can be explained on the basis that chlorides salts of certain metals are highly reactive towards sulphur. The extraction with $\mathrm{HgCl}_{2}$ is associated with the formation of white gummy precipitate, which may probably be due to the formation of the solid mercury sulphides or mercury salts of sulphur heterocycles. The same explanation can also be given for $\mathrm{BaCl}_{2}$. The other chloride salts like $\mathrm{NaCl}, \mathrm{ZnCl}_{2}$ and $\mathrm{AlCl}_{3}$ and $\mathrm{KI}$ on the other hands do not exhibit the same phenomenon which may probably be due to low reactivity of their cations towards sulphur compounds, due to which all these solutions showed low desulphurization yields.

The $\mathrm{HCl}$ solution is also found effective for desulphurization of heavy residue, which may be explained on the fact that the chloride salts of the heavier sulphur compounds are formed during the extraction process, which distribute in the polar acidic layer of the acid solution and hence easily extracted. The high desulphurization efficiency of arsenic oxide solution can be attributed to high reactivity of arsenic towards sulphur compounds, which is already reported ${ }^{26}$.

Lead is highly reactive metal towards sulphur bearing hydrocarbons particularly thioles, as its use for desulphurization of lighter hydrocarbons in different forms has been reported earlier ${ }^{28,29}$, but in case of heavy residue, the percentage of aromatic sulphur compounds is higher than thioles and sulphides. Therefore, the overall desulphurization yield is poor for lead acetate. Sulphuric acid also exhibits poor desulphurization yield which may be attributed to high concentration (acidity), which is not a suitable medium for the distribution of aromatic sulphur compounds, which requires an alkaline medium rather than an acidic medium.

\section{Desulphurization of Commercial furnace oil}

Like heavy residue, commercial furnace oil also contains high molecular weight sulphur compounds out of which the aromatic sulphur heterocycles e.g, thiophene, benzothiophenes and dibenzothiophenes are of main concern. Desulphurization of commercial furnace oil was also viewed. The data in the Table-2 shows that in case of furnace oil, the desulphurization yields obtained with $\mathrm{NaOH}(10 \%), \mathrm{HgCl}_{2}(10 \%), \mathrm{ArO}_{3}(5 \%), \mathrm{Ca}(\mathrm{OH})_{2}(10 \%)$ and $\mathrm{HCl}$ (1N) are quite appreciable, attaining 62.94, 67.68, 65.61, 69.76 and $65.11 \%$ desulphurization, respectively. On other hand the poor desulphurization yield is attained with other solutions. The percent desulphurization attained with aqueous solutions of $\mathrm{NaCl}(10 \%), \mathrm{KI}(10 \%)$, Pb-acetate $(10 \%), \mathrm{ZnCl}_{2}(10 \%)$, $\mathrm{AlCl}_{3}(10 \%)$ and $\mathrm{H}_{2} \mathrm{SO}_{4}(1 \mathrm{~N})$ was $20.85 \%, 13.23 \%, 38.74 \%, 46.49 \%, 42.4$ $\%, 17.57 \%$ and $32.38 \%$, respectively.

High desulphurization yields by $\mathrm{NaOH}$ and $\mathrm{Ca}(\mathrm{OH})_{2}$ can be explained as due to their capability of solubilizing the acidic sulphur compounds by providing an efficient alkaline medium. Due to high polarity of sulphur heterocycles, their distribution is more pronounced in these ionic solutions, which can be seen from their high desulphurization yield as compared to kerosene and diesel oil. Similarly, high desulphurization yield of $\mathrm{HgCl}_{2}$ is attributed to its high reactivity towards sulphur compounds, which is already mentioned. Although, the formation of gummy precipitate was not observed in this case, however, the distribution of sulphur compounds was greater in this medium. Similarly, high desulphurization yield of arsenic oxide may be attributed to its very reactive nature towards sulphur compounds, forcing the aromatic sulphur compounds to aqueous solution which was easily removed by the separation of oily and aqueous media. Pronounced desulphurization shown 
by $\mathrm{HCl}$ was also due to its high polarity on the basis of which the polar sulphur compounds were shifted to the $\mathrm{HCl}$ solution.

The poor desulphurization efficiency exhibited by aqueous solutions of $\mathrm{NaCl}, \mathrm{KI}, \mathrm{ZnCl}_{2}, \mathrm{AlCl}_{3}$ and $\mathrm{Pb}$-acetate may be explained on the basis their low reactivity, due to which the sulphur bearing heterocycles were unable to shift from its oily phase. Salts of lead are although very reactive towards thioles, forming lead thiolates, which is extensively practiced in precipitative desulphurization of lower distillates fractions, but in case of commercial furnace oil, the concentration of thioles is negligible as compared to substituted thiophenes, and the reactivity of the same metal is very low with these compounds, which in turn has resulted in poor desulphurization yield. Similarly, the low desulphurization yield obtained with the sulphuric acid can be explained on the fact that high acidity bearing sulphur compounds were unable to shift in the highly concentrated acidic solution of sulphuric acid.

\section{FTIR Analysis}

\section{Kerosene oil}

The FTIR spectrum of the original kerosene oil is provided in Fig. 2 (a) indicates the presence of marcaptans by a prominent band in the range of 2356 $\mathrm{cm}^{-1}$ due to S-H. ${ }^{31}$. A less intense medium band at $1376 \mathrm{~cm}^{-1}$ represents the $\mathrm{S}=\mathrm{O}$ asymmetric vibration, which gives an indication of the sulphones chlorides, sulphonates, sulphones or sulphoxides ${ }^{31}$. A wide band at $3417 \mathrm{~cm}^{-1}$ show the presence of the $\mathrm{NH}$ or $\mathrm{OH}$ which may corresponds to the bond associated with sulphonamides ${ }^{31}$. The FTIR spectra of the kerosene oil treated with $\mathrm{HgCl}_{2}(10$ $\%)$ and $\mathrm{Ca}(\mathrm{OH})_{2}(5 \%)$ are indicated in the Fig. 2 (b) and 2 (c). The spectra show that bands in this range indicating marcaptans S-H $\left(\right.$ at $\left.2365 \mathrm{~cm}^{-1}\right)$ and $\mathrm{S}=\mathrm{O}\left(\right.$ at $\left.1376 \mathrm{~cm}^{-1}\right)$ are weaker in intensity in (b) as compared to spectra of the original sample. While in case of spectrum (c), the band at $2356 \mathrm{~cm}^{-1}$ is missing, showing substituted thiole desulphurization has occurred.

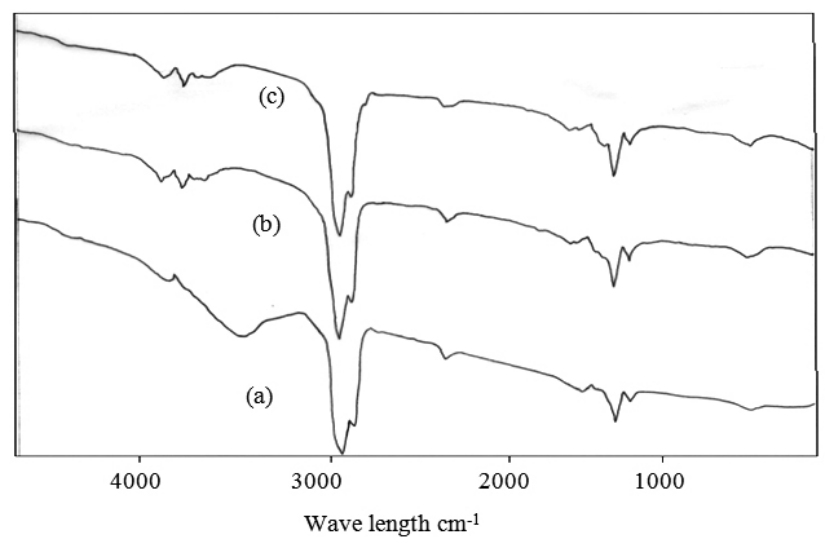

Fig.2. FTIR spectra of original and desulphurized kerosene oil (a) Virgin Kerosene (b) treated with $\mathrm{HgCl}_{2}$ (c) treated with $\mathrm{Ca}(\mathrm{OH})_{2}$.

\section{Diesel oil}

The FTIR spectrum of the original diesel oil is provided in Fig-3 (a) shows a medium broad band in the range of $2356 \mathrm{~cm}^{-1}$ which is given due to $\mathrm{S}-\mathrm{H}$ stretching vibration, indicating the presence of marcaptans. An intense peak in the range of $1380 \mathrm{~cm}^{-1}$ corresponding for $\mathrm{S}=\mathrm{O}$ bond, showing the presence of the sulphones ${ }^{31}$. The evidence of the presence of sulphides is given by a weak band centered at $1204 \mathrm{~cm}^{-1}$ produced by sulphidic $\mathrm{C}=\mathrm{S}$ bond. An intense band in the range of $1043 \mathrm{~cm}^{-1}$ indicates the presence of the sulphoxides emerging due to the S-O bonds. The spectra of the diesel oil treated with $\mathrm{HgCl}_{2}(10 \%)$ and $\mathrm{Ca}(\mathrm{OH})_{2}(5 \%)$ indicated in the Fig. 3(b) and 3(c), show a less intense band indicating marcaptans $\mathrm{S}-\mathrm{H}$ (at $2365 \mathrm{~cm}^{-1}$ ) while the bands corresponding for sulphoxides $\mathrm{S}=\mathrm{O}$ (at $1376 \mathrm{~cm}^{-1}$ ) are weaker in intensity in respective spectra, as compared with the spectrum of the original sample. While the bands representing sulphides and sulphones are totally missing.

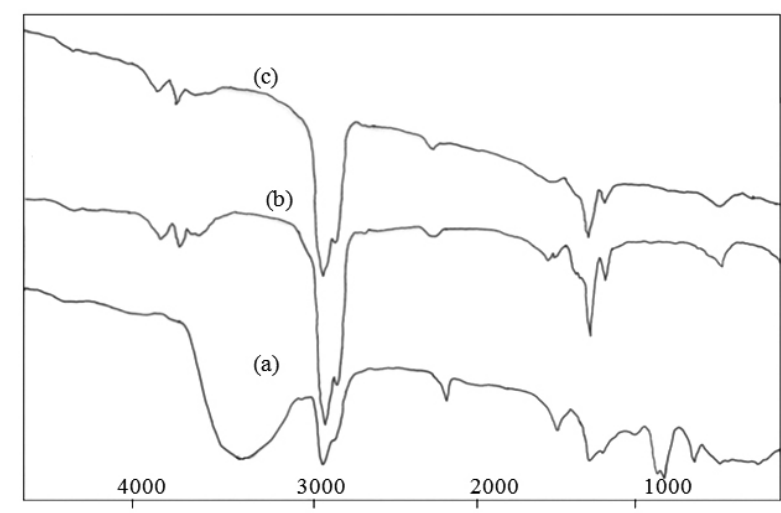

Wave length $\mathrm{cm}^{-1}$

Fig.3. FTIR spectra of original and desulphurized diesel oil (a) Virgin diesel (b) treated with $\mathrm{HgCl}_{2}$ (c) treated with $\mathrm{Ca}(\mathrm{OH})_{2}$.

\section{Heavy Residue}

The FTIR spectrum of the original heavy residue is provided in Fig 4 (a) shows the presence of the marcaptans giving a broad and intense band at 2343 $\mathrm{cm}^{-1}$, sulphoxides by a strong absorption band at $1374 \mathrm{~cm}^{-1}$ and sulphides by a weak band slightly near $1300 \mathrm{~cm}^{-1}$. The spectra of the heavy residue treated with $\mathrm{HgCl}_{2}(10 \%)$ and $\mathrm{Ca}(\mathrm{OH})_{2}(5 \%)$ indicated in the Fig 4(b) and 4 (c), respectively, which show the absorption band arising due to marcaptans is reduced in intensity in the spectrum (b) and completely missing in the spectrum (c), only the intensity of the band given for $\mathrm{S}=\mathrm{O}$ of sulphones is same. On the other hand, the band corresponding to sulphides is missing in both of the spectra.

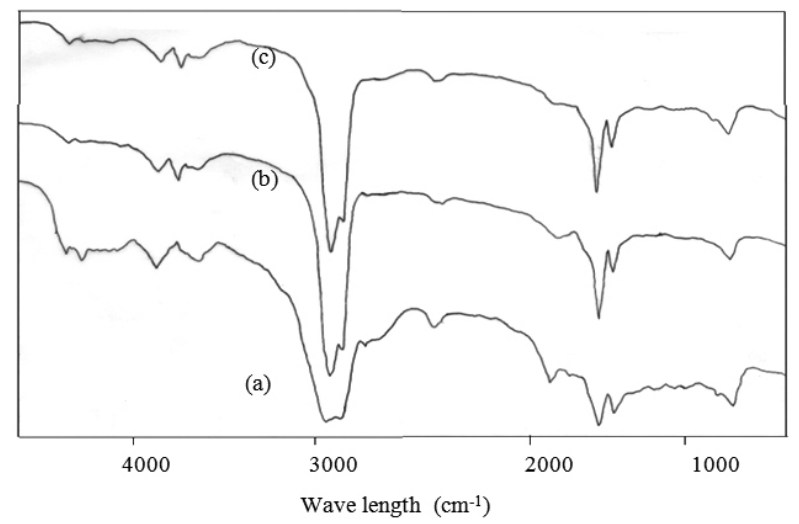

Fig.4. FTIR spectra of the original and desulpurized heavy residue (a) Virgin heavy residue (b) treated with $\mathrm{HgCl}_{2}$ (c) treated with $\mathrm{Ca}(\mathrm{OH})_{2}$.

\section{Commercial furnace oil}

The spectrum of the original commercial furnace oil is given in the Fig.5 (a) showing a wide and a high intensity band at near $2355 \mathrm{~cm}^{-1}$, which characterizes the presence of marcaptans. Similarly, at position $1374 \mathrm{~cm}^{-1}$, a strong band is present which corresponds to $\mathrm{S}=\mathrm{O}$ of sulphones. The presence of sulphides is also indicated by a strong absorption band at $1164 \mathrm{~cm}^{-1}$. A band lying at position $1031 \mathrm{~cm}^{-1}$ corresponds to sulphoxides $\mathrm{S}=\mathrm{O}$ bond. The FTIR spectra of the commercial furnace oil treated with $\mathrm{HgCl}_{2}(10 \%)$ and $\mathrm{Ca}(\mathrm{OH})_{2}(5 \%)$ represented by Fig. $5(\mathrm{~b})$, and $5(\mathrm{c})$, respectively indicating the characteristic bands showing marcaptans configuration have relatively lower intensity, indicating the decrease in their concentration, while the characteristic absorption band for sulphones remains same in intensity and bands correspond to sulphides and sulphoxides are missing in the spectra of the treated samples. 


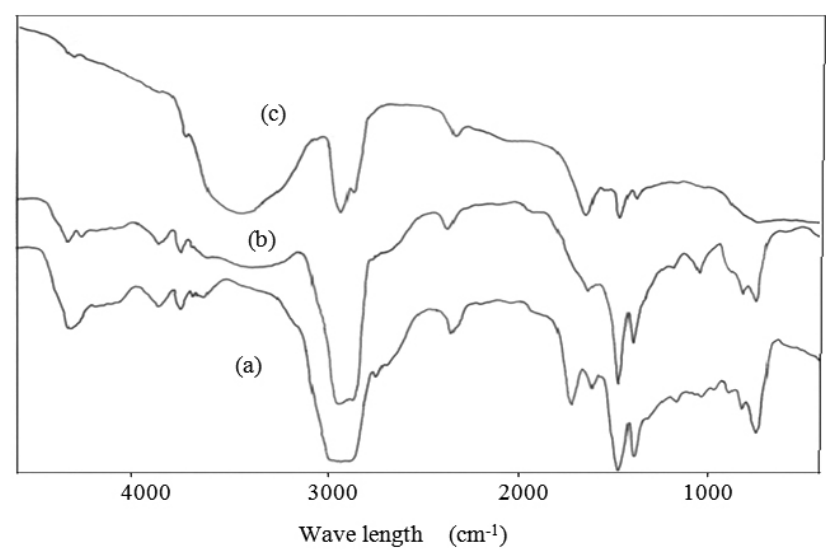

Fig.5. FTIR spectra of original and desulphurized commercial furnace oil. (a) Virgin furnace oil (b) treated with $\mathrm{HgCl}_{2}$ (c) treated with $\mathrm{Ca}(\mathrm{OH})_{2}$.

The above discussion clearly depicts that the liquid-liquid extraction has removed much of the sulphur in the form of sulphides, marcaptans and sulphones.

\section{CONCLUSION}

Desulphurization of petroleum fractions by extraction with ionic solutions is an economic, simple and an efficient process. The sulfur contents of the kerosene, diesel oil, heavy residue and commercial furnace oil can be lowered upto $60,71,68$ and $70 \%$ respectively. The process has advantage of easy handling and use of less expensive reagents over the conventional hydrodesulphurization, oxidative desulphurization and adsorptive desulphurization etc, which make use of expensive chemicals, equipments, difficult to process and are more time consuming. The process, however, has room for improvement to achieve better results.

\section{REFERENCES}

1. J. J. McKetta, Petroleum Processing Hand Book, Marcel Dekker. 1992.

2. D. R. Qu, Y. G. Zheng, H. M. Jing, Z. M. Yao, W. Ke, Corros. Sci. 48 1960, (2006).

3. J. Hucinska, $A d v$. Mater. Res. 6, 16, (2006).

4. J. Hucinska, Mater. Corros. 55, 292, (2004).

5. J. Chow, R. J. Kopp, P.R Portney, Science. 302, 1528, (2003).

6. D. I. Stern, Chemosphere. 58, 163 (2005).

7. M. Balat, G. Ayar, C. Oguzhan, H. Uluduz, U. Faiz, Ener. Sour. Part B. 2, 213, (2007).

8. I. Krylov, V. Emelyanov, E. Nikitina, B. Vizhgorodskii, K. Rudyak, Chem. Technol. Fuels Oils. 41, 423, (2005).

9. H. Yi, J. Hao, X. Tang, Energy Policy. 35, 907 (2007).

10. J. W. Beer, Prog. Energy Combust. Sci. 26, 301, (2000).

11. J. J. McKetta, Petroleum Processing Handbook, CRC press, 1992.

12. W. A. E. McBryde, Annals of Science. 48, 103 (1991).

13. H. Faghihian, M. Vafadar, T. Tavakoli, Iran. J. Chem. Chem. Eng. 26, 19, (2007).

14. S. Shokri, M. A. Marvast, M. Tajerian, Petr. \& Coal. 49, 48, (2007).

15. F. Jiménez, V. Kafarov, M. Nuñez, Chem. Eng. J. 134, 200, (2007).

16. K. Hüseyin, Y. Zebra, Pet. Sci. Technol. 23, 285 (2005).

17. W. Wang, S. Wang, H. Liu, Z. Wang, Fuel. 86, 2747, (2007).

18. H. Zhao, S. Xia, P. Ma, J. Chem. Technol. Biotechnol. 80, 1089, (2005).

19. W. Wang, S. Wang, Y. Wang, H. Liu, Z. Wang, Fuel Process. Technol. 88, 1002, (2007).

20. C. Huang, B. Chen, J. Zhang, Z .Liu, Y. Li. Ener. Fuel. 18, 1862, (2004).

21. W. H. Lo, H.Y. Yang, G. T. Wei. Green Chem. 5, 639, (2003).

22. L. Z. Pillon, Interfacial Properties of Petroleum Products, CRC Press, 2007.

23. C. Yen, G. Zhu, D. Xia. Fuel Process. Techn. 79, 135, (2002).

24. A. H. Lee, C. S. Cho, Fuel Process. Techn. 64, 141, (2000).

25. G. D. Hobsons, Modern Petroleum Technology, Applied Sciences, 1975.

26. S. Liu, B. Wang, B. Cui, L. Sun, Fuel. 87, 422, (2008).

27. D. Q. Eliche, E. C. Rodríguez, A. L. Jiménez, Microp. and Mesop. Mater. 99, 268, (2007)

28. J. P. Nehlson, J. B. Benziger, I. G. Keverkidis, Ind. Eng. Cehm. Res. 42 $6919,(2003)$

29. A. S. Salem, H. S. Hamid, Chem. Eng. Technol. 20, 342, (1997).

30. Hasebe, Nobuyasu. United States Patent, No. 3937795, 05/439616.

31. D. H. Pvia, G. M Lurpman, G. S Kriz, Introduction to Spectroscopy. Harcourt Brace College. 1996. 